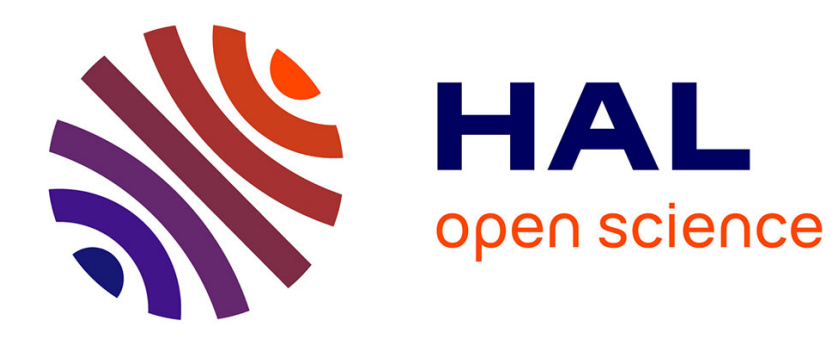

\title{
Figures of gestural manipulation in digital fictions
}

Serge Bouchardon

\section{To cite this version:}

Serge Bouchardon. Figures of gestural manipulation in digital fictions. Routledge. Analyzing digital fiction, pp.159-175, 2013, 9780415656153. hal-01972084

\section{HAL Id: hal-01972084 \\ https://hal.science/hal-01972084}

Submitted on 7 Jan 2019

HAL is a multi-disciplinary open access archive for the deposit and dissemination of scientific research documents, whether they are published or not. The documents may come from teaching and research institutions in France or abroad, or from public or private research centers.
L'archive ouverte pluridisciplinaire HAL, est destinée au dépôt et à la diffusion de documents scientifiques de niveau recherche, publiés ou non, émanant des établissements d'enseignement et de recherche français ou étrangers, des laboratoires publics ou privés. 


\title{
Figures of gestural manipulation in digital fictions
}

\author{
Serge Bouchardon \\ Université de Technologie de Compiègne, laboratoire COSTECH \\ serge.bouchardon@utc.fr
}

\section{Serge Bouchardon}

Associate Professor, University of Technology of Compiegne, France

e-mail: serge.bouchardon@utc.fr

Website: http://www.utc.fr/ bouchard/

Postal address: 40 rue de Clamart 60200 Compiègne - France

\section{Biography}

Serge Bouchardon graduated in literature from La Sorbonne University (Paris, France). After working as a project manager in the educational software industry for six years, he wrote his dissertation on interactive literary narrative and is currently Associate Professor in Communication Sciences at the University of Technology of Compiegne (France). His research focuses on digital creation, in particular digital literature.

Latest book published: "Littérature numérique: le récit interactif", Hermes Science Publishing, Paris, dec. 2009.

Website: http://www.utc.fr/ bouchard/

\section{Abstract (50 words)}

Digital fictions often rely on gestural manipulations from the reader. In this essay, I propose a semio-rhetorical approach to analyze the role of these gestural manipulations in the building of meaning. These manipulations contribute to the constitution of figures that I call figures of manipulation. 


\section{Introduction: the manipulable dimension in digital creation}

At the end of the 1990s, online advertising banners depended essentially on animation. However, in recent years, there have been an increasing number of online advertisements which also call on an active manipulation on the part of the user. It may be a question of moving an element on the screen ${ }^{\mathrm{i}}$, of activating a link ${ }^{\mathrm{ii}}$, or even entering text via the

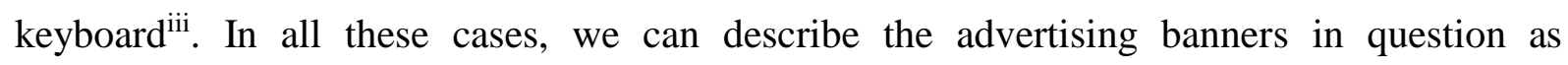
interactive, whether it be a question of apprehending an existing content, of activating another content, or of creating a new content by introducing new data (Bouchardon 2009).

In the domain of literary and artistic digital creation, interactive works have already existed for several decades. In an interactive creation, manipulations by the reader are therefore a prerequisite for the creation to unfold. The manipulations, in these interactive digital creations, are not radically new. In particular, there are many examples of literary works which require physical interventions on the part of the reader, for example the Cent mille milliards de poèmes by Raymond Queneau (Queneau 1961). Espen Aarseth has proposed the term "ergodic literature" to designate this sort of work: "in ergodic literature, nontrivial effort is required to allow the reader to traverse the text" (Aarseth 1997: 1). Nevertheless what is somewhat new in interactive digital creation is the fact that it is the text itself, and not only the physical medium, which acquires a dimension of manipulation. A digital text, as well as being a text provided for reading, can also provide an opportunity for manipulation (Ghitalla \& Boullier, 2004). This dimension of the manipulation of the text, but also the whole range of semiotic forms, opens a large field of possibilities in interactive digital creations.

Currently theorists lack the tools, in particular the semiotic tools, to analyze this sort of creation. The aim of this chapter is thus to propose a method for semiotic - and in particular semio-rhetorical - analysis of manipulations in digital creations, notably digital fictions. I will limit the field of study to online creations, in the twin domains of creative advertising and literary and artistic creation. To this end, I will first of all address the gesture of manipulation in digital creations. I will then propose a model - based on a bottom-up approach - for the analysis of gestural manipulations ${ }^{\text {iv }}$. Utilizing this approach, I will end with the study of figures of manipulation in digital creations. 


\section{The gesture of manipulation in digital creations}

\section{Gesture and meaning}

Yves Jeanneret claims that the simple act of turning the page of a book "does not suppose $a$ priori any particular interpretation of the text; ... [B]y contrast however, in an interactive work the fact of clicking on a hyperword or on an icon is, in itself, an act of interpretation" (Jeanneret 2000: 113). Jeanneret suggests that the interactive gesture consists above all in "an interpretation realized through a gesture" (Jeanneret 2000: 121). However, the distinction that Jeanneret proposes between turning a page and clicking on a hyperlink is not necessarily obvious and could be criticized. Moreover, we are stretching the limits of interpretation quite dramatically if we really accept that all clicking is interpretative (see e.g. Tosca this volume, Rustad 2009). Despite these caveats, we can nevertheless point out that, in an interactive work, the gesture acquires a particular role, which fully contributes to the construction of meaning.

Let us illustrate this point with the short digital fiction Don't touch $m e^{\mathrm{v}}$. This work displays a photograph of a woman lying on a bed, as a voice - that of Annie Abrahams, the author starts telling a story. The narrative is about a dream that Annie Abrahams had when she was a teenager. This dream can be interpreted as the sometimes painful transition from teenage to adulthood for a young woman exposed to the gaze and the desire of men. The interactor listens, but can experience at the same time an action with the mouse. Being passive, looking and listening without using the mouse is not always easy for the interactor, often prompted to click compulsively. If the interactor rolls the cursor over the picture, a text immediately appears on the screen, expressing the woman's refusal ("don't touch me") and she changes positions. The vocal tale stops immediately and restarts from the beginning. On the fourth attempt of caress with the mouse, the window closes. 


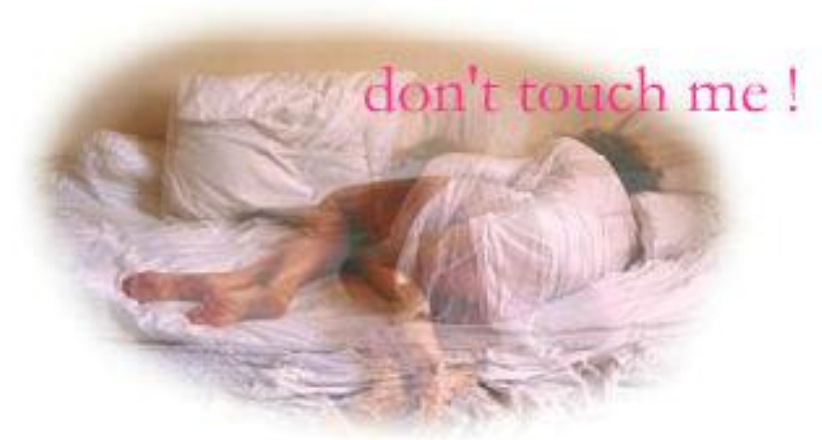

Figure 1: "Don't touch me" by Annie Abrahams (2003).

The story Don't touch me has a vocal, visual (the young woman displayed) as well as writtentextual dimension (the three messages of refusal). It also has a gestural dimension: it is through the action of the user that the vocal narrative makes sense. This is an interactive story insofar as it stages interactivity. The piece is indeed based on a play between interactivity and narrativity (cf. Ensslin 2012). Interactivity prevents narrativity insofar as the gesture of the user stops the narrative. The author plays on the apparent incompatibility between narrativity and interactivity to teach the user to resist his desire to click, but also to apprehend differently the representations - especially online - of the female body. The vocal narrative can only be interpreted through the gesture of the user: it makes sense because it is interactive. But how can we analyze the functioning of this gesture of manipulation in a more precise way?

\section{A repertoire of gestures}

In the manipulation of interactive online creations, we are dealing with a range of different gestures: clicking, double-clicking, right-click (PC), moving the mouse (or moving the finger on the touchpad), maintaining the pressure of the finger, lifting the finger, tapping a key on the keyboard, but also sometimes breathing or speaking into a microphone, moving the head in front of a webcam, etc. Given this diverse range, we need a repertoire of gestures which acknowledge that these acts appear as distinct units. We are nevertheless faced with a difficulty: the gestures involved in digital manipulation are constantly evolving, and depend on the available devices. In this respect the wiimote (the controller for Nintendo's Wii console) has led to a considerable evolution in the repertoire of gestures that are available to a player. But even without considering video games consoles or the virtual reality devices available on digital installations, the simple fact of being able to use two fingers for 
zooming/dezooming with the track-pad of the latest Macintosh computers offers unprecedented possibilities for manipulation in online creations.

With other devices, the repertoire of gestures will clearly be even wider than with just the mouse-keyboard input. This is the case for the manipulation gestures available with interactive tables $^{\mathrm{vi}}$, or yet again when interacting with a $3 \mathrm{D}$ tactile desktop ${ }^{\mathrm{vii}}$. But to the extent that we limit our study to the analysis of online creations, we will be above all concerned with the standard input interfaces mouse and keyboard, while recognizing that certain websites already propose the possibility for navigating with other input interfaces such as the webcam, the microphone, or indeed any sort of everyday object in experiments with augmented reality (e.g. a box of chocolate cereals ${ }^{\text {viii }}$ ).

If we wish to abstract ourselves from the contextual dimension of technological innovations, we can pose the following question: can a gesture, considered as a distinct unit, also be considered as a meaningful unit, independently of the context in which it is inscribed and/or the media resource to which it is applied? I wish to put forward here the idea that there may be expectations linked to a certain gesture performed in a certain context. The context recreates a situation that has already been encountered and in which a certain gesture has given rise to a relevant result. It is thus the gesture in a given context which is linked to an expectation, and not the gesture in itself: for example, the expectation is different when one clicks to validate a choice or when one clicks on a hyperlink. These expectations are in part the fruit of the construction of conventions. Thus, the roll over / roll out, by which a media resource can be made to appear/disappear, can trigger the expectation of an unveiling (Bouchardon 2008). Just as there may be significant features linked to movements in an animated sequence (Saemmer 2009), we can speak of the possible significant features linked to the gesture of manipulation in context.

\section{The analysis of the gesture of manipulation}

\section{Gesture and action}

The gesture is considered here as a single unit (pressing a key on the keyboard or the mouse button, elementary movement of the mouse, etc). The single unit is linked to a material interface. The action is considered as a sequence of gestures (for example drag and drop), and 
has a more global meaning linked to a double coupling with a context and a process. Often, the relevant medium (with which the gesture interacts) is indeed a process, and not the final result. Even more than in the case of animation, manipulation brings into play what Philippe Bootz calls the "depth of the device" (Bootz 2004): in the case of manipulation, the signs are fundamentally "dual" signs, which bring into play elements which are situated both on the side of the programme and on the side of the screen.

With the aid of this approach to gestures, I will now propose a model for the analysis of gestures of manipulation in online digital creations. This model is the result of a bottom-up approach. Alexandra Saemmer, Philippe Bootz and myself have analyzed a corpus of 100 advertising banners and 20 literary digital creations to build this model.

\section{The five levels of analysis of manipulation}

I will now propose a terminology which makes it possible to distinguish five levels in the articulation of signs, which correspond to five levels of analysis. I will illustrate this five level-model by analyzing an advertising banner, considered here as a short interactive narrative. On the site bannerblog.com there is reference to an advertising banner for the "Amanco" company ${ }^{\mathrm{ix}}$. In this banner, there is a representation of a toilet (see Figure 2, on the left). The iconic representation of the cubicle in the advertisement reinforces the impression of a confined space. The task for the user is to flush the toilet. On the handle at the end of the chain from the cistern there is written the instruction "pull". The chain is animated with a movement from top to bottom which encourages the interactor to pull. The interactor has to pull the mouse towards him/herself while keeping the button pressed: this gesture mimes the action of pulling the chain of the cistern downwards.

Once the chain is pulled, a violin and hands appear from the bottom of the toilet bowl (see Figure 2 in the centre). One hears some music played on the violin. The slogan then appears: "Not every sound deserves to be heard". Then the name of the product appears: "silentium PVC soundproof pipes" (see Figure 2 on the right). If the interactor pulls on the chain again, another instrument appears from the bottom of the toilet bowl. Overall, three instruments (a violin, a saxophone, an accordion) follow one another. 

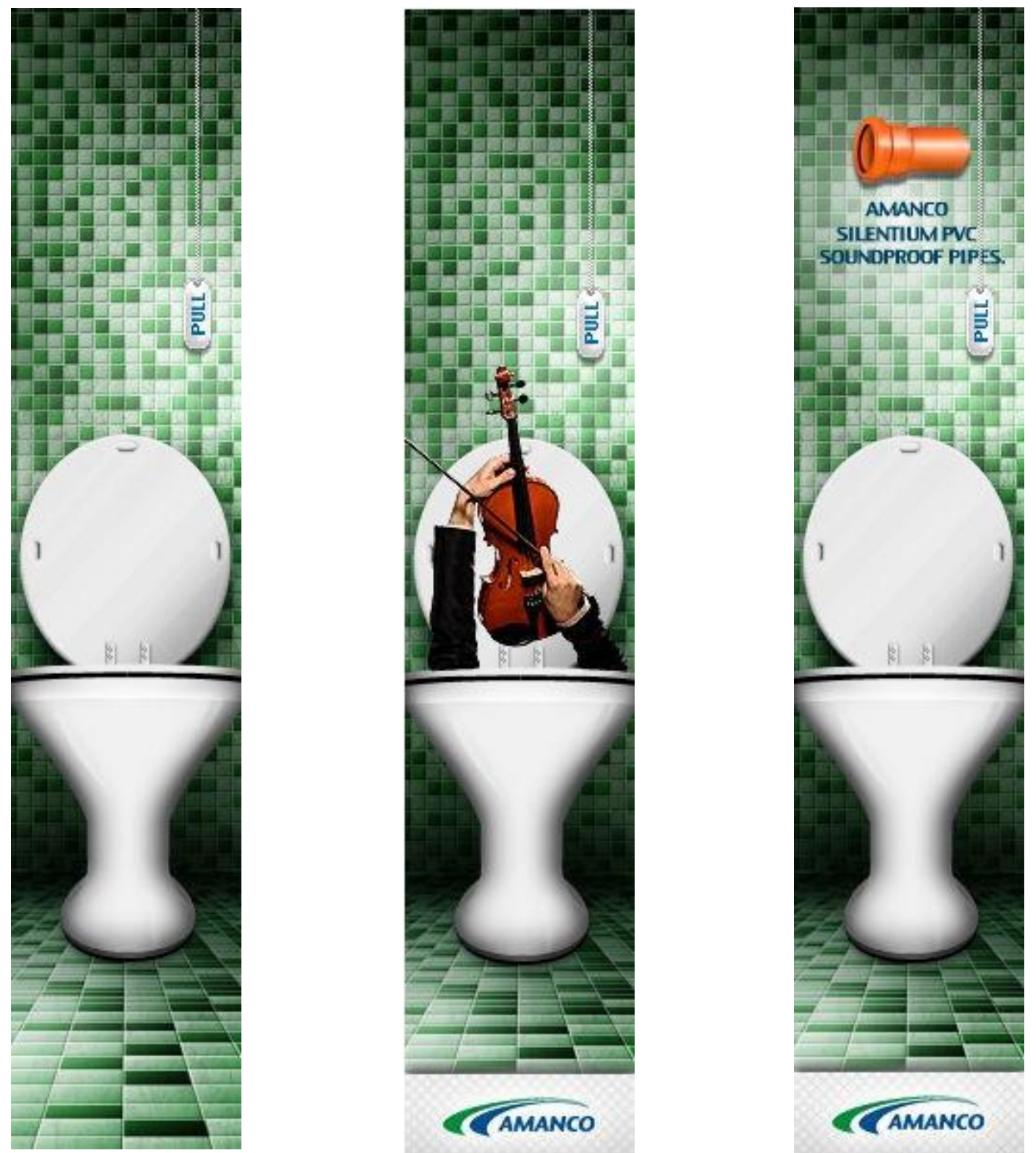

Figure 2: The three stages of the online advertising banner for the Amanco firm (2009).

\section{1 - The gesteme}

This is the first level of articulation, the lowest level. It results from the coupling between a physical act and an input interface (for example, the fact of moving the mouse ${ }^{\mathrm{x}}$ or pressing a key). The gesteme corresponds to a distinct semiotic unit.

In the Amanco advertisment, the interactor presses the button of the mouse (after having positioned the cursor on the word "pull"); keeps it pressed while moving the mouse; and then 
releases the button. We have here several gestemes which intervene in this manipulation: pressing the button; moving the mouse; releasing (the reverse of pressing).

\section{2 - The acteme}

The acteme is constructed on the basis of the gestemes. It corresponds to a sequence of gestemes and results from the coupling between the gesteme and the process on which the manipulation bears.

There are three types of actemes (which are distinguished by the coupling between the sequence of gestures and the process which is manipulated):

- Actuator (change of state).

- Parametor (setting a parametric process).

For example, I use a scrollbar, which makes it possible to move horizontally or vertically.

- Perturbator (a co-managed process).

At a certain moment, a programme can take charge and do something incompatible with the guidance of the action. I can refer here to Astrid Ensslin's notion of "third generation cybertext", which emphasizes the role of the machine code taking over control (Ensslin, 2007). This is the case for example with the rabot-poète ${ }^{\mathrm{xi}}$ created by Philippe Bootz, or in certain creations of Rafael Rozendaal ${ }^{\mathrm{xii}}$ which play on the discrepancy between the manipulation of the mouse and the displacement of the arrow on the screen (visibility, appearance, speed, meaning, direction).

In my example above, there are two actemes: a parametor (I pull), and an actuator (I release), which triggers at the same time the appearance of a musical instrument and the associated sound.

\section{3 - The Semiotic Unit of Manipulation (SUM)}

The actemes are combined to form semiotic units of manipulation. In my example, the two second-level actemes together constitute a single SUM: pull-release.

Following Peirce, Jean-Marie Klinkenberg recalls that the icons are signs that are "motivated by resemblance" (Klinkenberg 2000: 193). In the icon, something from the physical world is recognized as such. In the same way, the SUMs bring to mind actions in the physical world. 
For example, the SUM Scratch can recall the action of scraping a surface. The SUM is thus iconic with respect to situations of manipulation in everyday life. It carries features of iconicity. In the Amanco advertisement, it is indeed interesting to note the iconic dimension of the SUM. The interactor is encouraged to make a gesture with the mouse that resembles the gesture in real everyday life when he/she pulls a toilet-chain.

\section{4 - Media coupling}

The media coupling results from the coupling of the SUM with the media context. The SUM, as we have seen, exhibits an iconic dimension. However, it is only through its coupling with actual media that the significant features will actually be realized. The realization of these features depends on the text, the image or the sound to which the gesture is applied, as well as the multimedia context and the cultural environment of the reader.

The wider the domain of intersection between the significant features of the gesture and the media to which it is applied (and the more the combination of features which are mobilized corresponds to the expectations of the reader related to the immediate context and his reading habits), the more the construction of meaning derives from what we may call conventional coupling ${ }^{\text {xiii }}$. When the field of intersection between the significant features of the gesture and of the media is diminished, there arises a differential between the expectations of the reader and the state actually accomplished by the manipulation: in this case we speak of nonconventional coupling (for example, the gesture of clicking on a link does not result in any activation, or a delayed activation, or yet again the activation of a multiplicity of elements).

\section{Significant features}

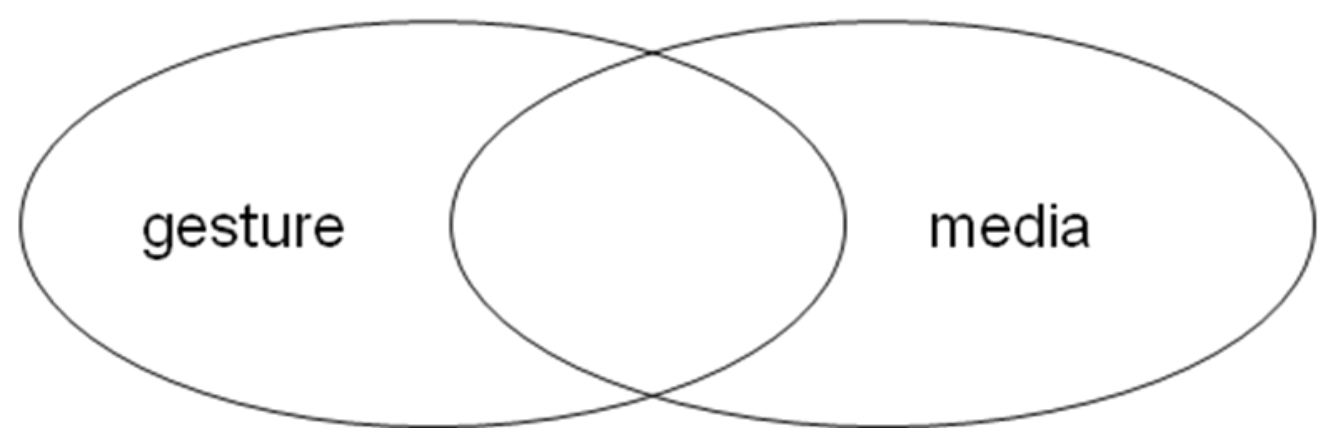


Figure 3: the field of intersection between the significant features of the gesture and of the media.

Every coupling between a SUM and the media is by nature "pluri-codal ", in the sense that it brings into play a number of "sub-statements each of which refers to a different code" (Klinkenberg 2000: 232).

There are three sorts of coupling:

- Simultaneous (simultaneous coupling between a gesture and the media) ;

- Consecutive (coupling between a gesture and the media which closely precede and/or follow it) ;

- Deferred (coupling between a gesture and a media result which is very distant in time $)^{\mathrm{xiv}}$.

In the Amanco advertisement, we can identify here two media couplings (one is simultaneous, the other is consecutive):

- The coupling of the SUM pull-release with "pull" and with the image of a toilet-flush (a conventional coupling);

- The coupling of the SUM pull-release with the incongruous appearance of the violin considering the media context, here the toilet-bowl (non-conventional coupling).

This second coupling takes into account the initial state, the manipulation gesture and the final state. In the final state, a violin appears instead of water after having pulled the toilet-flush. This appearance of the violin in the toilet-bowl is incongruous considering the media context, but also perhaps with respect to the interactive gesture: I pull downwards and something arises upwards (in this case a violin). The general isotopy (toilet bowl, confined space) reinforces the media couplings.

\section{5 - Interactive discourse}

This is the level of a complete interactive sequence of media couplings. We are here at the level of "discourse" (Klinkenberg 2000). Indeed it is often by taking into account the whole interactive discourse that the gesture of manipulation becomes fully meaningful. 
In our example, after the interactor has pulled the chain a first time, an expectation is created: pulling the chain causes a violin to appear. One can speak of a perturbation of the expectation when it is another instrument that appears the second time (a saxophone), then the third time (an accordion). The actuator of level 2 is then reinterpreted as a perturbator. The user may think that there is a random choice between the various instruments. However, if he/she continues to actuate the flush-handle, he/she realizes that the sequence: violin - saxophone accordion is always the same. He/she can finally reinterpret the perturbator as a parametor. The strength of this advertisement lies in its capacity to encourage the user to play and to replay the sequence so as to discover whether his/her expectations will be fulfilled or not.

\section{Figures of manipulation in digital creation}

We have seen that the semiotic units of manipulation, in context, constitute media couplings (a media coupling results from the coupling of the semiotic unit of manipulation with the media context). Non-conventional media couplings give rise to figures. According to Gérard Genette, a figure can be considered as "a gap between sign and meaning" (Genette 1966). Jean-Marie Klinkenberg (Klinkenberg 2000: 343) defines a rhetorical figure more precisely as "a dispositif consisting in the production of implicit meanings, so that the utterance is polyphonic". In interactive and multimedia writing, the polyphonic dimension of the figure also relies on the pluricodal nature of the content.

I shall now illustrate the construction of such figures. Digital literary and artistic works, notably digital fictions, do indeed largely call upon what we may call figures of manipulation. If we come back to our first example, the digital fiction Don't touch me by Annie Abrahams, we can now identify a non conventional coupling between a SUM (Move) and the media context insofar as there is a gap between the expectations of the interactor when he or she moves the mouse cursor and the result obtained with this manipulation (until the final white screen). The caress on the picture of the woman with the mouse cursor only interrupts and then brutally stops the course of the piece, giving rise to what could be called a figure of interruption.

I shall now analyze in detail first a figure of manipulation from another short piece and then a whole interactive narrative based on figures of manipulation. 
I shall take as an example the French creation entitled Anonymes version 1.0 ${ }^{\mathrm{xv}}$. Anonymes version 1.0 is an online fiction made of 24 scenes which can be accessed sequentially or nonsequentially. Each scene deals with the themes of anonymity and building of identity. Each scene is interactive: it is through the gesture of the reader/interactor that the scene can unfold. I shall focus in particular on the first scene, entitled "Nom-dit"xvi. On the homepage, a reactive zone constituted by the text "Anonymes" (anonymous) allows the user to access this first scene. A video turns in a loop, representing a man who gets up from an armchair, apparently so as to avoid being filmed. An accompanying soundtrack (maybe footsteps, or simply the noise of the video) also plays in a loop. A window is presented to the interactor accompanied by a text: "Type your name". The scene is thus waiting for an action by the interactor.

The interactor types a letter; but this letter, instead of remaining in the window, "flies off" and disappears from the window. The interactor is tempted to type in another letter, in particular to test whether the functioning will be the same. The second letter flies off too. The interactor can then rapidly type in several letters, a complete word, to see the letters dispersed over the space of the scene (see Figure 4). We arrive at a result similar to that of certain kinetic poems (letters spread over the space and in movement), but here the letters result from an action by the user (introducing data via the keyboard).

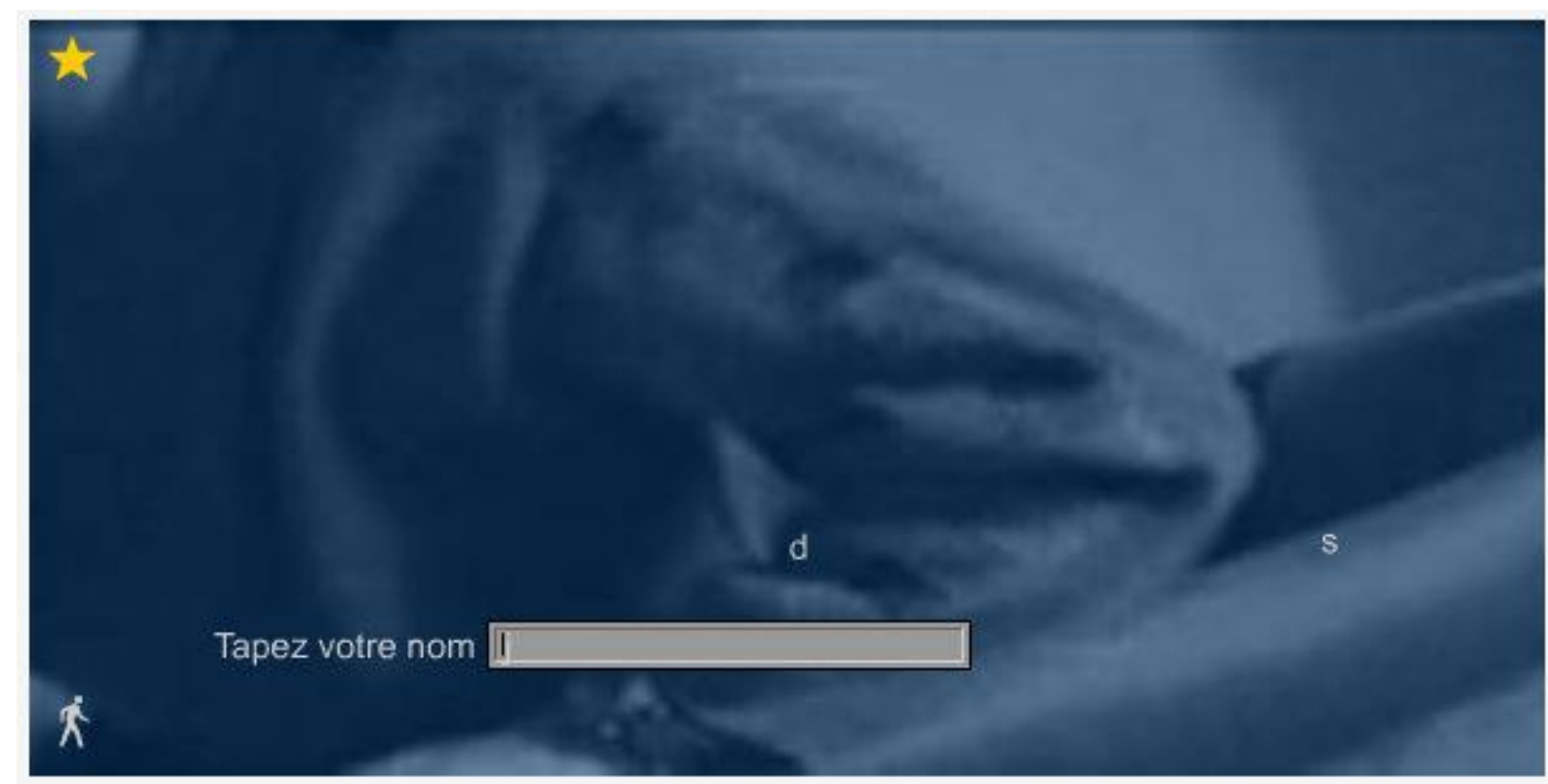

Figure 4: Anonymes version 1.0, scene "Nom-dit" (2000). 
The meaning of this scene (the letters of a name which fly off and disappear, unavoidably) is to be put in relation to the title of the whole creation, Anonymes. The figure which results from the gesture (the impossibility of inscribing one's name) is an echo of the video (a man who tries to avoid the field of the camera) and maybe also the soundtrack (sound of footsteps which move away). This scene does not have an end: we will remain anonymous indefinitely. The interactor does nevertheless have the possibility of returning to the homepage (icon in the top left corner), or to pass on to the next scene (icon bottom left).

To employ our terminology, the SUM mobilized here consists in "activating" (in punctual fashion, by pressing the keys of the keyboard). But this manipulation only takes on its full meaning when situated in the context of the media coupling, or even in the whole of the interactive discourse. We also witness a non-conventional coupling with the process of inscribing letters on the screen (here, the letters which fly off), to the extent that the functioning of the typing window is diverted from its usual function. The functioning of the typing window is part of the "encyclopaedia" (Klinkenberg 2000) of the user of a digital interface. In Klinkenberg's terminology, "encyclopaedia" refers to the knowledge mobilized by the reader; the encyclopaedia mobilized here depends on the ergonomics of man-machine interfaces and not on a linguistic semiology. A typing window conventionally makes it possible to type in a sequence of alphanumerical characters via the keyboard, without having the letters disappear in the course of the capture. Here, however, the window does make it possible to capture the letters of a text, but not to conserve them. The expectation of the user is disturbed.

Let us now analyze the process of construction. The typing window, associated with the text "Type your name", suggests that the programme is waiting for the gesture of typing a character on the keyboard. Now when one types a letter via the keyboard, one "inscribes" something which, at least in one's expectation, will be conserved. The typing windows in which one is asked to give one's identity are indeed often entitled "inscription" or "register". Incidentally, sometimes those who use a word processor for the first time do not understand why it is necessary to "save": for them, typing characters on a keyboard already has the value of a recording. The possible significant features linked to the action (typing a character on the keyboard) and the media context (the typing window associated with the text "Type your name") are: inscription, save. Here, however, the letters that have been typed in fly away and disappear. We have here the suppression of one possible significant feature - (lasting) 
inscription - because of the flight and disappearance of the letter. It is possible to type in characters, but not to inscribe them.

I form the hypothesis here that the construction of an interpretation occurs in particular with the repetition of a gesture. The functioning of this non-conventional coupling does indeed depend on the repetition. It is by repeating the gesture (here, typing letters on the keyboard) that the user progressively constructs the meaning of the scene (and understands that it is not simply a bug). In order to come to this conclusion s/he will take into account the whole context of the media and the interface. The media video (+ sound) then makes it possible to give a meaning to the scene. The content of the video (a man going away) takes on a meaning, as does its form (an indefinite loop). Indeed, possible significant features of a video loop are: circularity, constantly repeating itself. The significant feature of the video loop ("circularity") is superposed with the significant feature "inscription" (adjunction and then suppression). The form of the loop is associated here with the letters which unavoidably disappear from the typing window: caught up in this circularity, any seizure and any lasting inscription are impossible (we could also consider that the inscription on the screen is multiplied, but that it has no permanence). We have here a pluri-code construction between the significant feature "circularity" (the video loop) and the feature "inscription" (gesture coupled to the data capture window). The reader can draw the conclusion: "I will remain anonymous".

Other interpretations are possible. For example, at the level of the creation, we may consider that what is shattered here is the illusion of participating in the work. The reader cannot participate (although he/she does participate in the visual rendering, but only for himself/herself). What is portrayed here is a reflection on the interactivity and the contribution of the reader in so-called participatory works.

At a second level, it is necessary to resituate this scene in the totality of a discourse, by taking into account this preliminary interface, but also the whole set of the other scenes in this "version 1.0". On the homepage, one can see bees turning endlessly on the background of their hive. They too seem anonymous in the hive, but they also have an identity linked to what they are doing (queen, workers, drones), and consequently to their position in the hive. One can access the first scene by clicking on the corresponding cell of the honeycomb, or else by clicking on the title of the piece ("Anonymes"), which also constitutes a reactive zone (passing over it triggers the text "Enter"). It is this media context of interaction which must 
also be taken into account in the analysis of this figure, which could be called a figure of lability.

\section{Loss of Grasp: an interactive narrative based on figures of manipulation}

Numerous interactive digital fictions indeed play on the expectations of the reader by resorting to non-conventional media couplings, which can be analyzed in terms of figures. I shall now focus on the figures of manipulation to be found in an entire digital fiction.

Loss of Grasp ${ }^{x v i i}$ is an online interactive narrative in English, French and Italian. In this creation, six scenes tell the story of a character who is losing grasp on his life. In the first scene, the reader/interactor unfolds the narrative by rolling over the sentences which appear on the screen. Each time a sentence is rolled over, a new sentence is displayed. But after a while, when the sentence "Everything escapes me" appears, the mouse cursor disappears. The reader can keep rolling over each sentence, but without the reference point of the mouse cursor. Through this non-conventional media coupling, the reader experiences loss of grasp with his/her gestures.

The second scene stages the meeting of the character with his future wife, 20 years earlier. While the character "ask[s] questions to reveal her", the reader can discover the face of the woman by moving the mouse cursor. These movements leave trails of questions which progressively unveil her face. The questions themselves constitute the portrait of the woman (see Figure 5). 


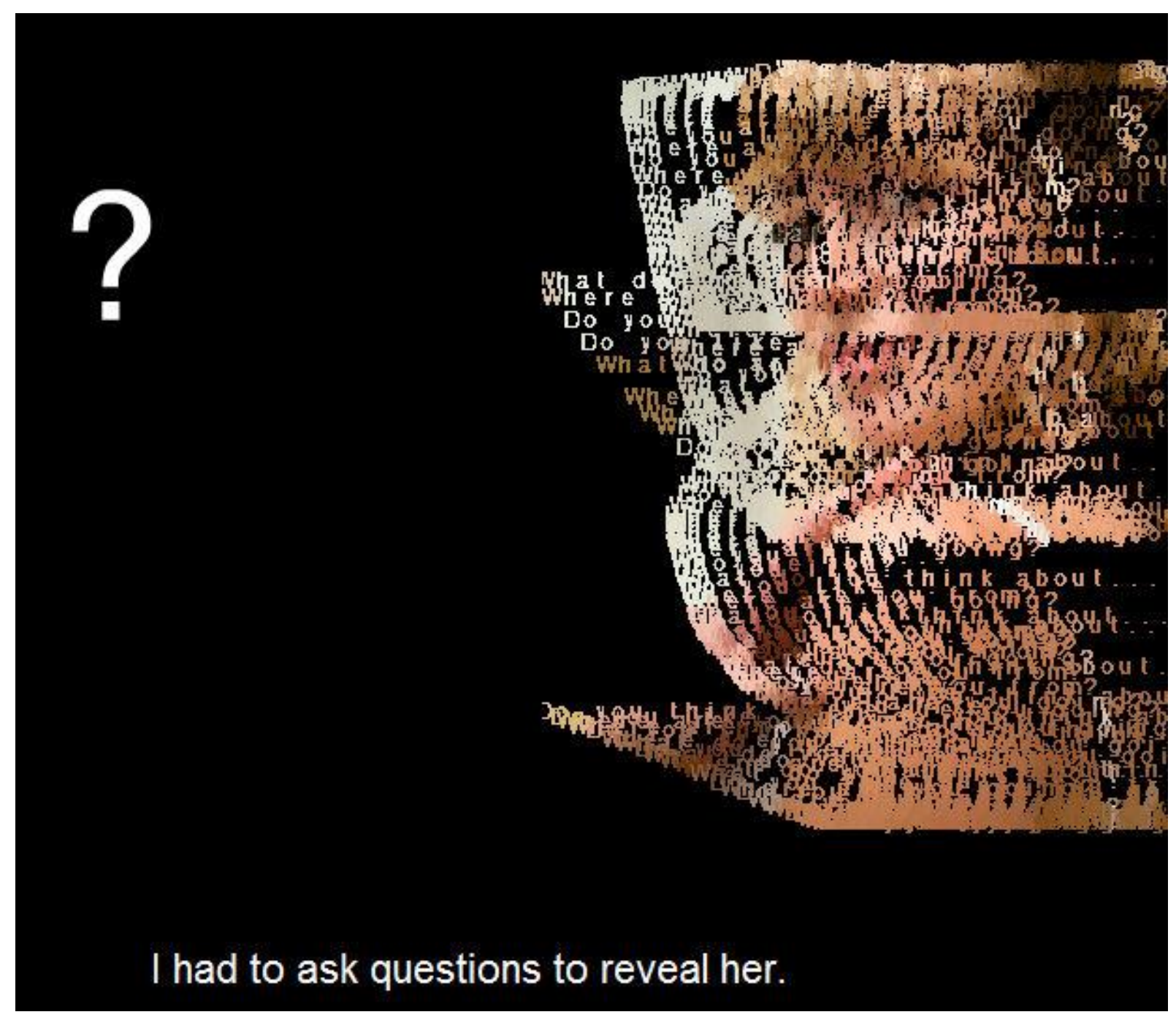

Figure 5: "Loss of Grasp" (2010), second scene. 
In the third scene, 20 years later, the character can't seem to understand a note left by his wife: "love poem or break up note?" The reader can experience this double meaning with gestures. If he/she moves the mouse cursor to the right, the text will unfold as a love poem; if he/she moves the cursor to the left, the order of the lines is reversed and the text turns into a break up note (see Figure 6).

\section{want all our friends to know that}

I don't want to stay with you

From the first day, I have wondered how you can believe th

I love you

My love

Has disappeared

Indifference

Is more vivid than ever

The charm of our encounter

Has dissolved

Love poem or break up note?

Figure 6: "Loss of Grasp", third scene. 
In the fourth scene, the character's teenage son asks his father to read an essay he wrote on the notion of "hero". But the character cannot focus on the words and "can only read between the lines". If the reader clicks on the words of the essay, sentences appear - made up of letters from the text itself - such as:

I don't love you.

You don't know me.

We have nothing in common.

I don't want anything from you.

You're not a model for me.

I want to make my own way.

Soon I will leave.

Paradoxically, the gesture of focusing on the text makes it fall apart and lets an implicit meaning appear (see Figure 7).

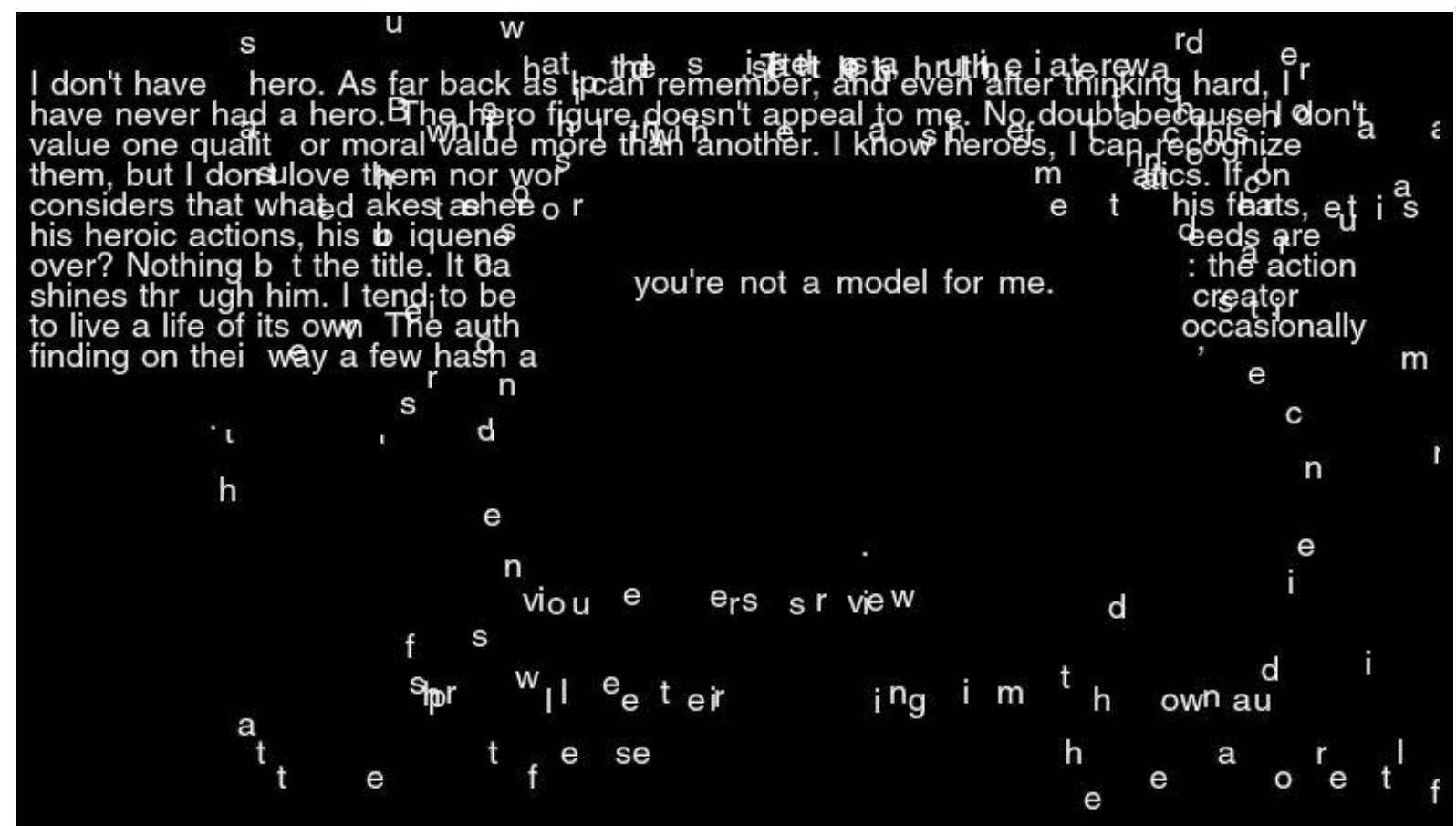

\section{But I can't focus on the words.}

Figure 7: "Loss of Grasp", fourth scene. 
In the fifth scene, even the character's own image seems to escape him. Via the webcam, the image of the reader appears on the screen. He/she can distort and manipulate it. The character/reader so "feel[s] manipulated".

In the last scene, the character decides to take control again. A typing window is proposed to the reader, in which he/she can write. But whatever keys he/she types, the following text appears progressively.

I'm doing all I can to get a grip on my life again.

I make choices.

I control my emotions.

The meaning of things.

At last, I have a grasp...

Here again, the reader is confronted with a figure which relies on a gap between his/her expectations while manipulating and the result on screen. Thus through his/her gestures and through various figures of manipulation - which could as a matter of fact appear as variations on a figure of loss of grasp - the reader experiences the character's loss of grasp in an interactive way.

\section{Conclusion}

In order to analyze interactive and multimedia digital creations, notably digital fictions, we need specific tools of semiotic analysis. The five-level analysis model presented in this essay has above all the heuristic aim of displaying the specificities of gestural manipulation in a digital creation and the role these manipulations play in the construction of meaning.

The gesture of manipulation allows for conventional and non-conventional couplings with a range of media. Non-conventional couplings give rise to figures. This essay is thus set in the context of an approach aiming at the formalisation of a rhetoric ${ }^{\text {xviii }}$ of interactive writing. We can put forward the hypothesis that there are indeed figures of rhetoric that are specific to interactive writing (Bouchardon 2007). We are dealing here with a category of figures in its own right - in addition to the classical figures of diction, of construction, of meaning and of thought - that we can call "figures of manipulation". Two points are to be emphasized here. On one hand, the notion of "figure" can - and this is what is new - take into account the 
gestures of the reader. On the other hand, interactive writing relies on figures of manipulation to a greater extent than other figures of meaning such as tropes. In a more general way, this chapter aims at making a contribution to the unveiling of the specificities of interactive writing.

\section{References}

Aarseth, E. (1997). Cybertext, Perspective on Ergodic Literature, Baltimore, John Hopkins University Press.

Bootz, P. (2004). "der/die Leser/Reader/Readers", dans F.W. Block, C. Heibach, K. Wenz (eds.), p0es1s. Ästhetik digitaler Poesie/The Aesthetics of Digital Poetry, Ostfildern-Ruit, Hatje Cantz Verlag, 936-122.

Bouchardon, S. (2008). "The rhetoric of interactive art works", DIMEA 2008 Conference, $10^{\text {th }}-12^{\text {th }}$ September 2008, Athens, Greece, ACM Proceeding Series vol. 349, 312-318.

Bouchardon, S. (2009). Littérature numérique : le récit interactif, Paris, Hermès-Lavoisier.

Bouchardon, S., Lopez-Varela Azcarate, A. (2011). "Making Sense of the Digital as Embodied Experience”, CLCWeb: Comparative Literature and Culture. Vol.13 n³, Sep. 2011. ISSN 1481-4374.

Bouchardon, S. (2011). "Des figures de manipulation dans la création numérique", Protée volume 39 numéro1, Chicoutimi : Université du Québec à Chicoutimi, 37-46.

Ensslin, A. (2007) Canonizing Hypertext: Explorations and Constructions. London: Continuum.

Ensslin, A. (2012) "Computer Gaming". In Bray, J., Gibbons, A. and McHale, B.eds.). The Routledge Companion to Experimental Literature, London, Routledge.

Genette, G. (1966)., Figures 1, Paris, Seuil, 205-221. 
Ghitalla, F., Boullier, D., Gkouskou-Giannakou, P., Le Douarin, L., Neau, A. (2004). L'Outre-lecture: manipuler, (s')approprier, interpéter le Web, Paris, Editions du Centre Georges Pompidou.

Jeanneret, Y. (2000). Y a-t-il vraiment des technologies de l'information?, Paris, Editions universitaires du Septentrion.

Klinkenberg, J.-M. (1996). Précis de sémiotique générale, Brussels, De Boeck.

Pougeoise M. (2001). Dictionnaire de rhétorique, Paris, Armand Colin.

Queneau, R. (1961). Cent mille milliards de poèmes, Paris, Gallimard.

Rustad, H. (2009). "A Four-Sided Model for Reading Hypertext Fiction". In Hyperrhiz 06.

Saemmer, A. (2009). "Aesthetics of surface, ephemeral and re-enchantment in digital literature. How authors and readers deal with the lability of the electronic device", Cyberliteratures of the world, Neohelicon No. 36, Springer, 477-488.

Tosca, S (2013) IN THIS VOLUME. (add later)

All websites were accessed for the last time on 7 February 2012.

\footnotetext{
${ }^{\mathrm{i}}$ Example : http://www.bannerblog.com.au/2009/09/commbank_finances.php

ii Example : http://www.bannerblog.com.au/2009/09/fas_twitter.php

iii Example : http://www.youtube.com/watch?v=4ba1BqJ4S2M

iv This model is directly inspired by a proposition by Philippe Bootz. This essay owes much to a collective reflection in the framework of a research group - composed of Alexandra Saemmer, Philippe Bootz, Jean Clément and myself - on the semiotics and the rhetoric of digital creations.

v Abrahams Annie, Ne me touchez pas/Don't touch me, 2003, http://www.bram.org/toucher/index.htm

vi Cf. Jacob O. Wobbrock, Meredith Ringel Morris, Andrew D. Wilson, User-Defined Gestures for Surface Computing, CHI2009.

vii A taxonomy of gestures for interacting with a 3D desktop:

http://gizmodo.com/5371913/bumptop-3d-desktop-gets-unique-multi+touch-gestures?autoplay=true

viii $\mathrm{http}: / /$ www.youtube.com/watch?v=p3QgigeSE1s

ix http://www.bannerblog.com.au/2009/09/toilet.php (accessed 7 February 2012).

${ }^{x}$ One can decompose a continuous movement (such as moving the mouse) into different gestemes. Thus, the mickey may be considered as the moving unit of the mouse cursor equivalent to $1 / 200$ inch, or 8 pixels. This unit makes it possible to distinguish different gestemes in the physical manipulation of the mouse.

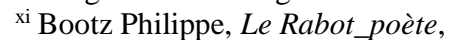

http://www.sitec.fr/users/akenatondocks/DOCKS-datas_f/collect_f/auteurs_f/B_f/BOOTZ_F/Animations_F/rabot.htm
} 
xii $\underline{\text { http://www.newrafael.com/websites/ }}$

xiii See Saemmer in this volume for more details concerning conventional or non-conventional couplings.

xiv This last sort of coupling allows what Philippe Bootz calls "double reading" (Bootz, 2004).

xv URL : http://www.anonymes.net/anonymes.html

xvi "Nom-dit" : literally "name-said", but there is a play on words here with the phonetically close expression "non-dit" (i.e. "unspoken").

xvii Bouchardon Serge and Volckaert Vincent, Loss of Grasp, 2010, http://lossofgrasp.com

This creation won the New Media Writing Prize 2011.

xviii Classical rhetoric comprises five main parts: invention, disposition, elocution, action and memory. Elocution is particularly attached to the literary and aesthetic aspect of the discourse. This is the aspect that is retained by "restricted rhetoric". This expression comes from Michel Pougeoise: "Amongst the advocates of this rhetoric that can be described as "literary" because it is interested essentially in the study of figures and style, we must mention J. Cohen, G. Genette, H. Morier as well as the $\mu$ group (Pougeoise, 2001). We are interested here in this restricted rhetoric: posing the question of a rhetoric of interactive writing, amounts to posing the question of a specificity of this writing in terms of style and in particular of figures. 